\title{
Protocol \\ Dissections of Larval, Pupal and Adult Butterfly Brains for Immunostaining and Molecular Analysis
}

\author{
Yi Peng Toh ${ }^{1, \dagger}{ }^{+}$Emilie Dion ${ }^{1, *,+}$ a and Antónia Monteiro ${ }^{1,2}$ \\ 1 Department of Biological Sciences, National University of Singapore, 14 Science Drive 4, \\ Singapore 117543, Singapore; toh.yi.peng.2014@vjc.sg (Y.P.T.); antonia.monteiro@nus.edu.sg (A.M.) \\ 2 Yale-NUS College, 10 College Avenue West, Singapore 138609, Singapore \\ * Correspondence: dion.emilie@ymail.com \\ + The authors contributed equally.
}

Citation: Toh, Y.P.; Dion, E.;

Monteiro, A. Dissections of Larval, Pupal and Adult Butterfly Brains for Immunostaining and Molecular Analysis. Methods Protoc. 2021, 4, 53. https://doi.org/10.3390/mps4030053

Academic Editor: Fernando Albericio

Received: 8 June 2021

Accepted: 31 July 2021

Published: 5 August 2021

Publisher's Note: MDPI stays neutral with regard to jurisdictional claims in published maps and institutional affiliations.

Copyright: (c) 2021 by the authors. Licensee MDPI, Basel, Switzerland. This article is an open access article distributed under the terms and conditions of the Creative Commons Attribution (CC BY) license (https:// creativecommons.org/licenses/by/ $4.0 /)$.

\begin{abstract}
Butterflies possess impressive cognitive abilities, and investigations into the neural mechanisms underlying these abilities are increasingly being conducted. Exploring butterfly neurobiology may require the isolation of larval, pupal, and/or adult brains for further molecular and histological experiments. This procedure has been largely described in the fruit fly, but a detailed description of butterfly brain dissections is still lacking. Here, we provide a detailed written and video protocol for the removal of Bicyclus anynana adult, pupal, and larval brains. This species is gradually becoming a popular model because it uses a large set of sensory modalities, displays plastic and hormonally controlled courtship behaviour, and learns visual mate preference and olfactory preferences that can be passed on to its offspring. The extracted brain can be used for downstream analyses, such as immunostaining, DNA or RNA extraction, and the procedure can be easily adapted to other lepidopteran species and life stages.
\end{abstract}

Keywords: brain dissections; butterflies; caterpillars; pupa; Bicyclus anynana

\section{Introduction}

Despite having small brains, insects' cognitive abilities are impressive. They can process a large set of information from their environment and adjust their behaviour accordingly [1]. Many species possess remarkable learning and memorisation skills [2,3]. Examples of sophisticated behaviours include concept and category learning in honeybees [4], tool use in ants [5], facial pattern recognition in wasps [6,7], and counting ability in bees [8,9].

The neural mechanisms responsible for these sophisticated behaviours have interested researchers for decades (e.g., [10-12]). These mechanisms were largely investigated in the fruit fly (e.g., [13-16]), honey bee (e.g., [17-19]), and more recently in other insects, such as crickets (e.g., [20-22]), mosquitos (e.g., [23]), or cockroaches (e.g., [24,25]), among others. Recently, studies on butterflies have also increased, motivated by the large diversity of behaviours that they can perform.

Butterflies are becoming a popular system in the fields of evolutionary neurobiology and neuroethology because they use a large set of sensory modalities for their survival and reproduction [26]. They process visual [27], olfactory [28], auditory [29], and gustatory [30] signals to help them forage, search for a host plant, select mates, avoid predators, or migrate. They can also memorise information from their environment and adjust their behaviour accordingly (e.g., [31,32]). Butterflies' visual and olfactory systems are also crucial mediators of reproductive isolation and speciation [33,34].

The growing exploration of the butterflies' neurobiology prompted the development of experimental techniques for producing relevant molecular and neuroanatomical data. Brain dissections are an essential step in the experimental process (e.g., [35-37]). Protocols describing the dissection of Drosophila brains are currently available [38-42], but a detailed description of butterfly brain dissections at various developmental stages is still lacking. 
Here, we describe the process of larval, pupal, and adult butterfly brain removal using a video. We also provide a complete written description of the processes, with a list of necessary tools and chemicals. The dissection methods can be applied to different butterfly species, and the brains can be used for DNA or RNA extraction, or for immunostaining. We record the dissection process in the Bush brown butterfly Bicyclus anynana, which is especially interesting due to its plastic and sex-role reversed courtship behaviour [43-46]. Individuals are also capable of learning visual and olfactory cues [47-49], and they can transmit the learned odour preferences to their offspring $[48,49]$. Because the molecular basis of these unique behaviours can begin to be examined at the level of the brain, it is important to extract this organ for downstream analyses.

We dissected the brains of two-day-old butterflies, those of pupae at $30 \%$ development, and those of 5 th instar larvae. These specific ages were chosen because B. anynana adult individuals showed a change in sex-pheromone and wing-pattern preferences on day two after exposure to the newly emerged females [47,48]. The 30\% pupal development corresponds to the critical stage where variation in hormone levels influences adult courtship behaviour $[50,51]$. We chose to dissect 5 th instar larval brains because they are bigger at this stage, and they provide higher amounts of RNA and DNA. However, B. anynana larvae start preferring novel food odours from the 3rd instar, and keep the same preference until pupation [49]. To show that our methods can be easily applied to other families and individuals of various sizes, we also dissected the brains of adults, pupae, and caterpillars of Pieris canidia (family: Pieridae) at the same stages as B. anynana, and adults of two additional species from the Nymphalidae and Papilionidae.

\section{Experimental Design}

All materials and equipment needed for brain dissections are described in Figure 1. Figure 2 presents the anatomy of a larval head, adult head and of a pupa.

\subsection{Materials}

- Curved forceps (Dumont; Dumont Switzerland, Montignez, Switzerland; Cat. No.: 11274-20);

- $\quad$ Superfine dissecting forceps (Dumont; Dumont Switzerland, Montignez, Switzerland; Cat. No.: 82027-402);

- $\quad$ Blade holder (Swann-Morton No. 4; Swann-Morton, Sheffield, UK; Cat. No.: 0934);

- $\quad$ Surgical blades (Swann-Morton No. 4; Swann-Morton, Sheffield, UK; Cat. No.: 0115);

- Two dissection silicone plates (Dragon Skin 30 Mould Making Silicone Rubber; Cat. No.: 0751635278417, Petri plate; Sigma-Aldrich; Sigma-Aldrich, Singapore; Cat. No.: P5981-100EA). Use black or red silicon to best see the white brains, or place a black background underneath a transparent silicon plate;

- $\quad$ Glass spot plate (PYREX ${ }^{\mathrm{TM}}$; Corning, Corning, NY, USA; Cat. No.: 722085);

- Insect pins (BioQuip; BioQuip, Rancho Dominguez, CA, USA; Cat. No.: 1208B2);

- Glass slides (Biomedia, Singapore, Cat. No.: BMH.880102);

- $\quad$ Plastic pipettes (unbranded, Singapore), $1000 \mu \mathrm{L}$;

- Filter tips (Maximum Recovery, Axygen, Union City, CA, USA; no. TF-1000-L-R-S);

- Microcentrifuge tubes 1.5 mL (Eppendorf, Hamburg, Germany; Cat. no.: T9661-500EA). 


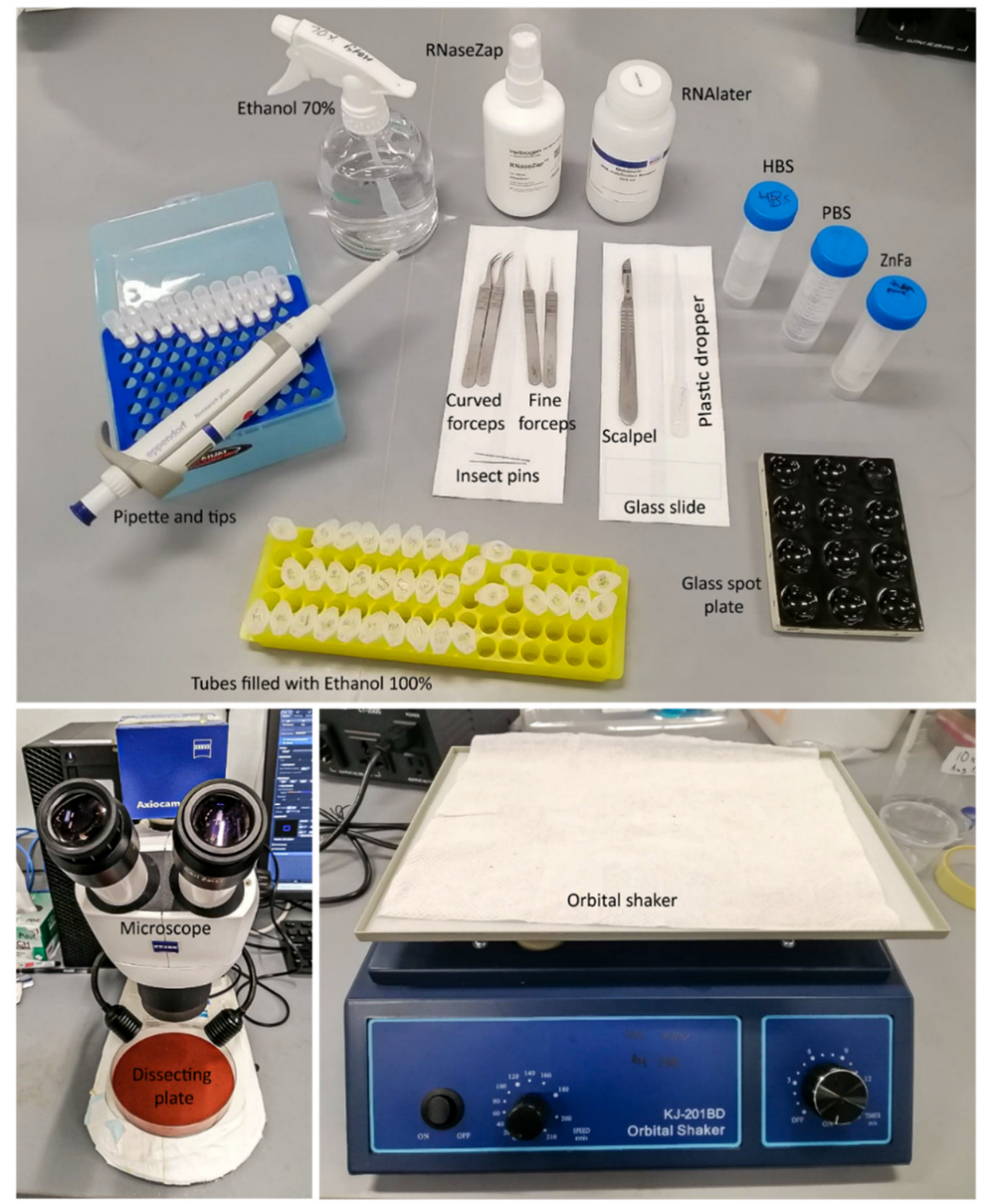

Figure 1. Equipment and materials needed for the dissection of adult, pupal, and larval brains.

\subsection{Equipment}

- Zeiss Dissection Microscope (Carl-Zeiss, Jena, Germany; Stemi 305);

- Orbital Shaker (Kangjian, Jiangyan City, China).

2.3. Reagents and Solutions

- $\quad \mathrm{NaCl}$ (Sigma-Aldrich; Sigma-Aldrich, Singapore; Cat. No.: S9888-500G);

- $\quad \mathrm{KCl}$ (Sigma-Aldrich; Sigma-Aldrich, Singapore; Cat. No.: P9541-500G);

- $\quad \mathrm{CaCl}_{2}$ (Sigma-Aldrich; Sigma-Aldrich, Singapore; Cat. No.: C1016-100G);

- $\quad \mathrm{ZnCl} 2$ (Sigma-Aldrich; Sigma-Aldrich, Singapore; Cat. No.: 208086-100G);

- $\mathrm{K}_{2} \mathrm{HPO}_{4}$ (Sigma-Aldrich; Sigma-Aldrich, Singapore; Cat. No.: P3786-500G);

- Sucrose (Sigma-Aldrich; Sigma-Aldrich, Singapore; Cat. No.: S0389-1KG);

- HEPES (Sigma-Aldrich; Sigma-Aldrich, Singapore; Cat. No.: H3375-100G);

- $16 \%$ Formaldehyde (ThermoFisher Scientific, Singapore; Cat. No.: 28908);

- Ethanol absolute (ThermoFisher Scientific, Singapore, Cat. No.: 64175);

- $\quad$ RNALater ${ }^{\circledR}$ RNA Stabilisation Reagent (Qiagen, Singapore, Cat. No.: 76104); 
- $\quad$ RNAseZap ${ }^{\mathrm{TM}}$ RNase Decontamination Solution (ThermoFisher Scientific, Singapore, Cat. No.: AM9780);

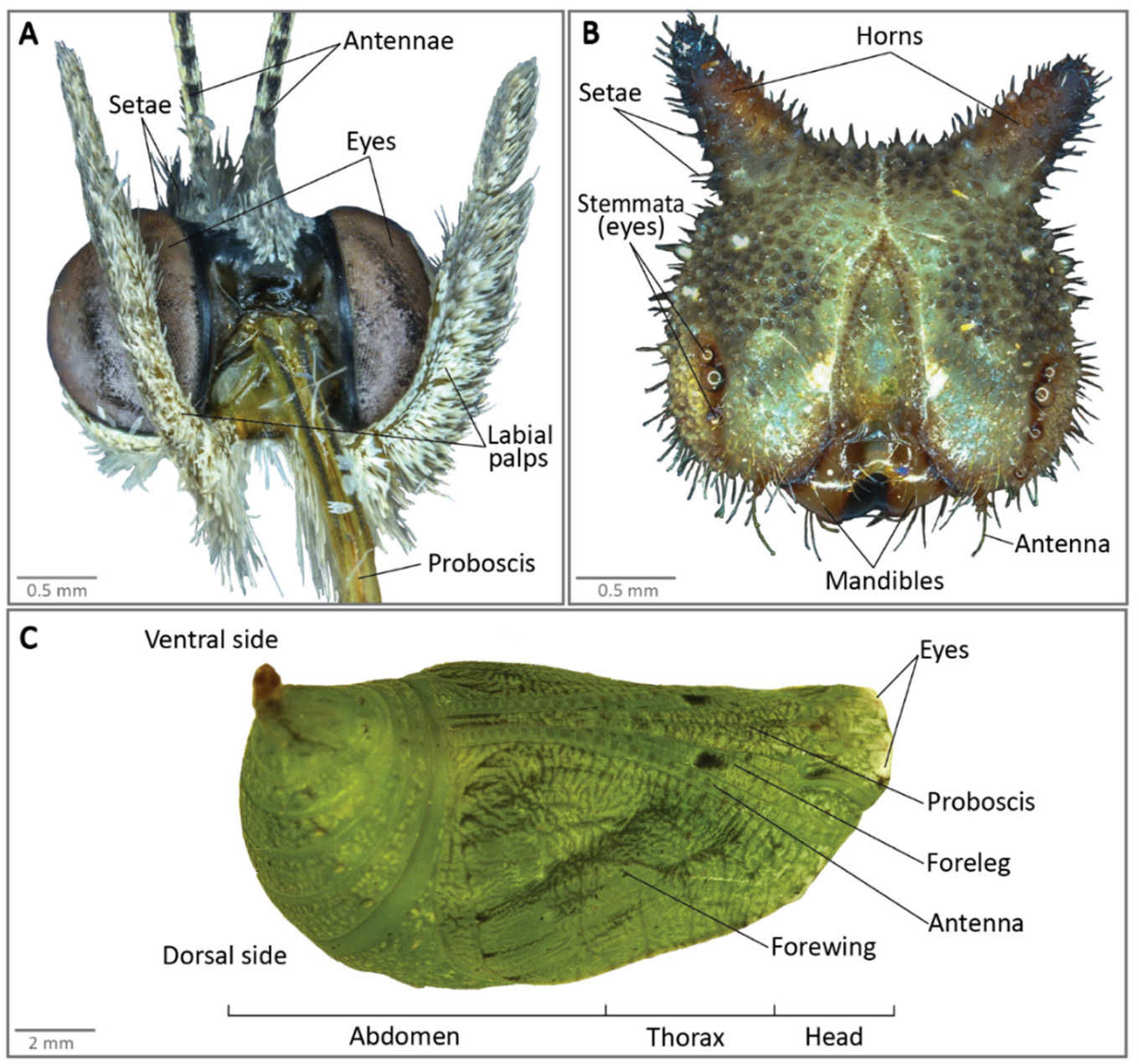

Figure 2. Anatomy of (A) a B. anynana butterfly head (front view), (B) a caterpillar head (front view), and $(\mathbf{C})$ of a pupa.

\section{Dissection of Adult Brains}

3.1. Preparation for Dissection

- Freeze anaesthetise the butterflies in a $-20^{\circ} \mathrm{C}$ freezer for 3-4 min;

- Wash the dissection tools and plates in $70 \%$ ethanol prior to dissection;

- $\quad$ Place a few drops of HEPES-buffered saline (HBS) onto a dissection plate using a plastic pipette, and set it aside (see recipe for HBS and all other reagents at the end of this article);

- If the brain tissues need to undergo immunostaining, fill a well in the spot plate with ZnFA solution using a plastic pipette, and set it aside before starting any dissection. If the brains are used for DNA or RNA extraction, fill the RNAse-free Eppendorf tubes with about $300 \mu \mathrm{L}$ of $100 \%$ ethanol or RNAlater, respectively. Place only up to 3 brains in the same well (for immunostaining). Number of brains to be pooled in one tube varies with the amount of DNA or RNA needed for downstream analyses;

A CRITICAL STEP If DNA or RNA work is involved, it is recommended to wipe the equipment with RNAseZap in step 2, and use a micropipette and filter tips instead in steps 3 and 4 . 


\subsection{Dissection Procedure}

\subsubsection{Exposure of Adult Brains}

- Take the butterfly out of the freezer and place it on a second clean dissection plate. The first series of steps are performed dry. Detach the head of the butterfly from the rest of the body using a pair of superfine dissecting forceps. Pull the head away from the body using your dominant hand while pressing down on the wings with the other hand. Ensure the point of pull is as close to the head as possible, to reduce the amount of thoracic tissue needed to be removed (Figure 3A);

- Remove the rest of the butterfly from the dissecting plate, leaving only the head. There will be some remaining thoracic regions left on the back of the head most of the time. Secure the head from moving with the forceps in your non-dominant hand, while pulling away the thoracic region with the other forceps in your dominant hand (Figure 2B). Remove the thoracic tissue until you can visualise the connection point of the labial palps to the head (Figures $2 \mathrm{~A}$ and $3 \mathrm{C}$ );

- Detach the labial palps and proboscis (Figures 2A and 3C,D) by pulling them hard away from the head. The easiest and fastest way to completely remove the palps and the proboscis is to grip them from the back of the head and pull them away from the head using the forceps in your dominant hand (Figure 3D), while gently pressing the part of the head where the proximal ends of the labial palps are located, using the other forceps in your non-dominant hand;

- Using a pair of insect pins, gently scrape off the setae that are attached to the cuticle surrounding the head. Gently press the head down with one insect pin while scraping the setae off with another (Figures 2A and 3E);

A CRITICAL STEP Be careful not to apply too much pressure when scraping near the eye, as a slight increase in pressure will damage the optic lobe. This step will reduce the number of setae floating on the dissecting solution, and allow for easier exposure of the brain tissue in the later steps;

- Detach the antennae (Figures 2A and 3F) using a pair of curved forceps. Pull the antennae hard away from the head using the forceps in your dominant hand, while gently pressing down, to the extent of just touching the head with the other forceps in your non-dominant hand (Figure 3F);

- Gently pick up the head using a curved forceps and transfer it into the previously prepared dissection plate with a few drops of HBS (enough to cover the tissue fully, about $180 \mu \mathrm{L}$ here) for subsequent exposure of the brain tissue (Figure 3G);

- $\quad$ Secure the head between the curved forceps and fully submerge it into HBS before exposing the tissue;

A CRITICAL STEP The head will tend to float on the surface of the saline solution at first. It is critical to ensure it is fully submerged (by securing the head between the ends of the forceps and then sinking it in the plate so that the saline solution fully covers the head). This ensures that the brain will be exposed within the solution and not outside of it, reducing tissue damage;

- Secure the head with the curved forceps facing upwards, to get a grip on the region of the cuticle in between the two eyes (Figure $3 \mathrm{H}$ );

- Make a small tear in the cuticle between the eyes (Figure 2I) and use it as an opening point to remove the rest of the cuticle (Figure 3J);

- Pull out any easily accessible trachea, using curved forceps in your dominant hand (Figure 3K).

Note: If the brains are used for DNA and RNA extraction, skip Section 3.2.2 (Fixation), and continue the dissection procedure directly as described in Section 3.2.3 below. 

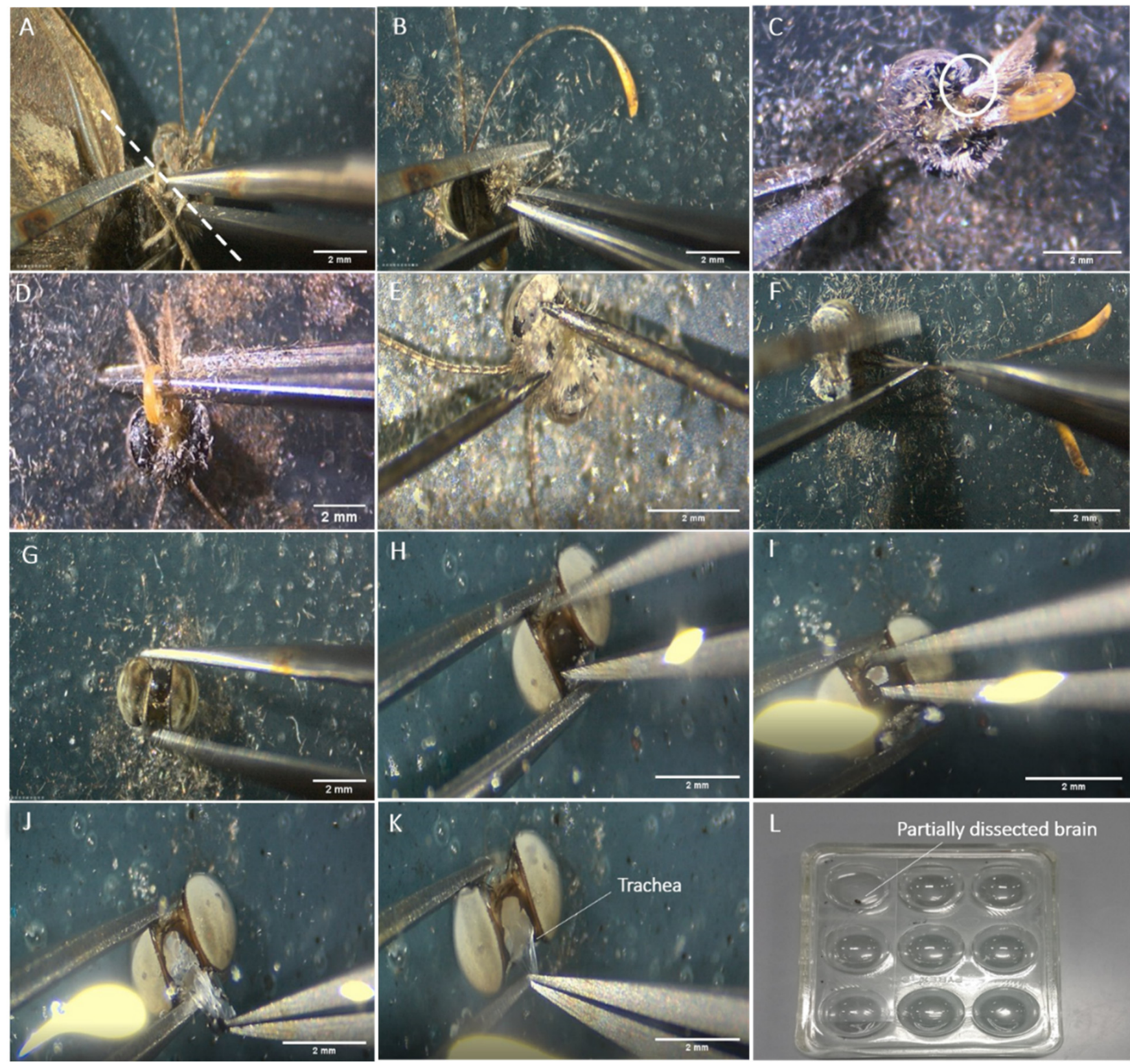

Figure 3. Exposure of an adult brain and fixation. Steps in $(\mathbf{A}-\mathbf{G})$ are performed dry while $(\mathbf{H}-\mathbf{L})$ are submerged in solution. (A) The ideal point of pull when detaching the head of the adult from the rest of the body is indicated by the white dashed line. (B) The remaining thoracic regions attached to the butterfly head are grabbed with fine forceps and pulled away. (C) The thoracic region is removed until the proximal ends of the palps are seen (circled in white). (D) The labial palps and the proboscis are then pulled away from the head. $€$ The setae attached to the front and back of the cuticle are scraped off gently using insect pins, to prevent setae from clouding the surface of the dissecting solution in the later steps. (F) The antennae are subsequently removed. $(G)$ The head is picked up gently using curved forceps and transferred to a dissecting plate with HBS. (H) The head is secured with curved forceps to allow easier access to the cuticle in between the two eyes (frontal view). (I) A small tear is made in the piece of cuticle in between the two eyes. (J) The brain is exposed with the region of the cuticle in between the two eyes removed, subsequently exposing the trachea underneath. (K) The sticky white trachea just below the surface of the cuticle are removed. (L) The exposed brain is submerged in a ZnFA solution in a spot plate well, and the opening is covered with a glass slide to prevent evaporation of the solution and drying of the tissues. The glass plate is subsequently placed on an orbital shaker with a setting of 80-100 rmp for 16-20 h. 


\subsubsection{Fixation of Adult Brains for Immunostaining}

- Gently lift the head up with the exposed brain with the curved forceps and transfer it into a well filled with ZnFA solution (Figure 3L). Cover the well with a glass slide, then place the well plate on an orbital shaker and agitate it for 16-20 $\mathrm{h}$ at 80-100 rates per minute (rmp);

- After fixing overnight, transfer each fixed brain from the well into a dissection plate with a few drops of HBS by gently lifting it up using the curved forceps;

- Again, the brain might float on the surface of the solution. Grab a small part of the brain with the curved forceps and fully submerge it into the solution (Figure 4A).

A CRITICAL STEP Ensure to cover the well with the glass slide so that the fixing solution does not evaporate overnight.

\subsubsection{Dissection of the Adult Brain}

- Gently make a superficial tear in the cuticle of one eye (Figure 4B);

- Then start breaking off the cuticle into small pieces and remove it gently (Figure 4C);

A CRITICAL STEP Do not pull strongly, or the whole optic lobe will be detached from the rest of the brain. If the cuticle cannot be broken off, try to dislodge it via a rotating pull. The region of the cuticle nearest to the central brain sticks very closely to the brain tissues, and is hard to remove via normal pulling without damaging the tissues. The easiest way to remove it will be to pull it along the orientation of the eye, going from the dorsal to the ventral point in a circular motion, and breaking it off naturally;

- After clearing out the cuticle of one eye, remove the piece of non-brain tissue that is loosely attached to the back of the brain, with small bits of cuticle on it (Figure 4D);

- $\quad$ Proceed to remove the cuticle of the other eye by repeating steps 3 and 4;

- $\quad$ Remove the easily accessible trachea (Figure 4E);

- Then, scrape away the main body of the ommatidia and the basement membrane of the retina from the optic lobes, using a pair of insect pins (Figure 4F). These tissues are darkly coloured;

A CRITICAL STEP Do not scrape too hard as the basement membrane is firmly attached to the lamina of the optic lobe. The lamina gets easily destroyed with just a little pulling pressure;

- Remove any remaining trachea by pulling gently with a curved forceps (Figure 4G), while pressing the brain down with an insect pin or by using insect pins to scrape them off the brain tissue (Figure $4 \mathrm{H}$ );

- Transfer the fully dissected brain back to the well for downstream immunostaining using a pipette (Figure 3I), or into an Eppendorf tube filled with RNAlater (for RNA extraction) or $100 \%$ ethanol (for DNA extraction). 


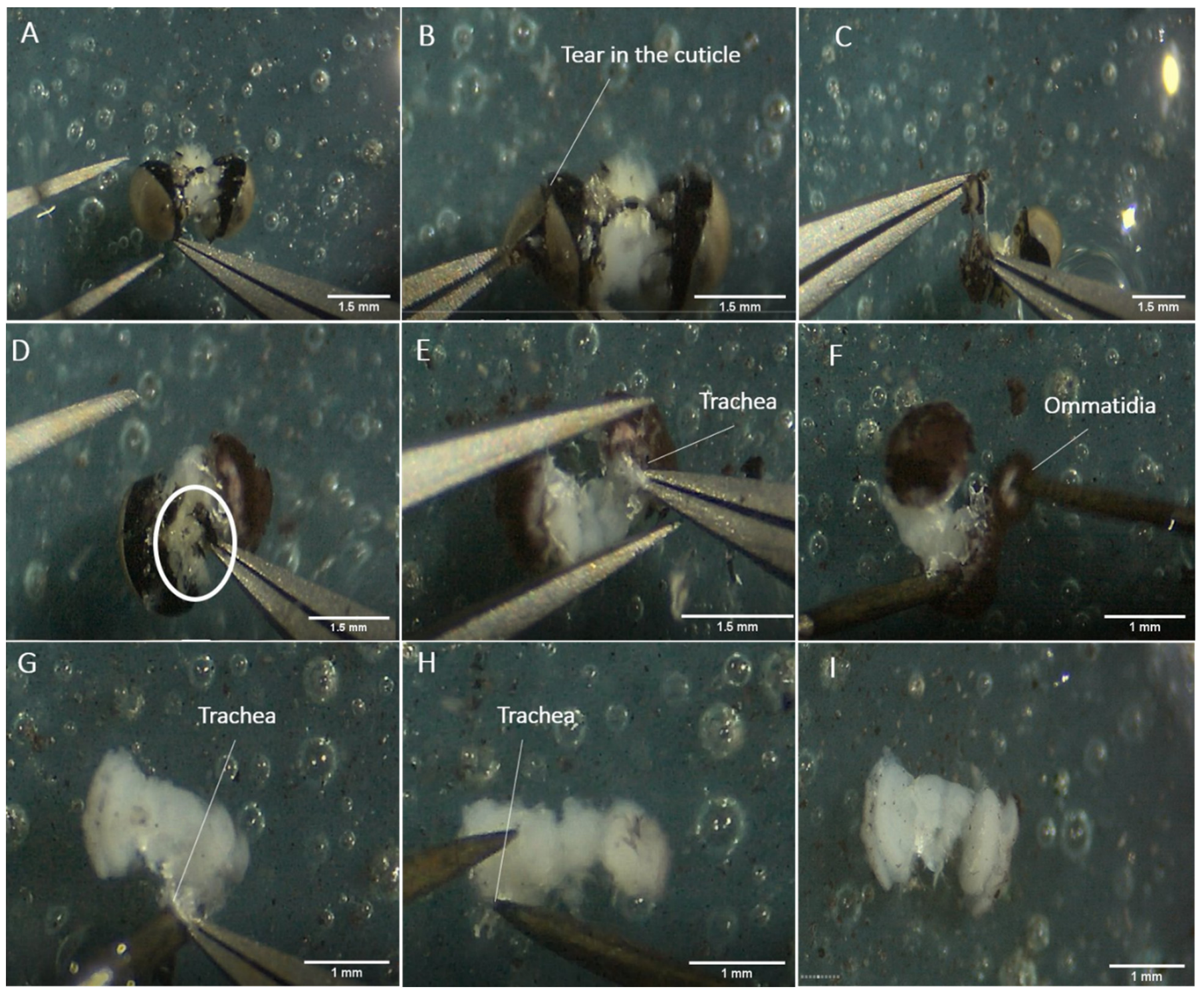

Figure 4. Dissection of an adult brain. (A) A small part of the brain is grabbed to submerge it fully in HBS. (B) While the brain is submerged, a superficial tear in the cuticle of one eye is made. (C) A small piece of cuticle is removed on the side of the eye. (D) The non-brain tissue that is loosely attached to the back of the brain is removed, as indicated by the white circle. (E) The cuticle of both eyes is removed, exposing some trachea. The trachea is the white, stringy, and sticky substance attached to the brain tissues. It is important to control the pulling force so that the brain tissues are not accidentally teared. (F) The ommatidia are packed together into a reddish-brown spongy tissue, and this is removed from one side of the eye. (G) Some trachea still attached is pulled away with curved forceps. (H) The remaining trachea can also be scraped away with insect pins. (I) The fully dissected brain can be used for further analyses.

\section{Dissection of Pupal Brains}

\subsection{Preparation for Dissection}

- $\quad$ Place the pupae on ice for about 15 min prior to dissection;

- Wash the forceps, scalpel, and dissection plate with $70 \%$ ethanol. If the brains are used for RNA extraction, use RNAzap instead;

- $\quad$ Prepare RNase-free Eppendorf tubes or well plates filled with the solution appropriate for the subsequent experiment, and place them close to the dissection microscope. For DNA and RNA extraction, prepare tubes with about $300 \mu \mathrm{L}$ of $100 \%$ ethanol and RNAlater, respectively. For immunostaining experiments, place about $500 \mu \mathrm{L}$ of the 
ZnFa fixative solution in the wells. Place a drop of cold PBS on the dissection plate (enough to fully cover the tissue, here about $500 \mu \mathrm{L}$ ).

\subsection{Dissection Procedure}

- Cut the pupae into two pieces at the base of the thoracic region using the scalpel blade, and move the head and thoracic regions (Figure 2C) into the drop of PBS (Figure 5A). The abdominal part of the cut pupa can be discarded;

- With one hand, hold the cut pupae inside the PBS drop using forceps. With the other hand, use the forceps tips to push the thorax cuticle down at the base of the head (Figure 5B). The junction between the head and the thorax will break, making a small opening in the cuticle (Figure 5C);

- Hold the cuticle head at the opening just made, and with the other hand, grab the thorax cuticle. Pull the thoracic region and all the tissue that come together (antennae, legs for example, Figure 2C) horizontally towards you while firmly holding the head cuticle (Figure 5D). After it is fully detached from the head cuticle, discard the thoracic tissue. The developing butterfly head and the dorsal side of the brain will be exposed at the bottom of the pupal cuticle (Figure 5E);

A CRITICAL STEP Do not pull the thoracic region upward. Pull gently in a horizontal direction to prevent the brain from tearing and being detached from the head capsule;

- Hold the pupal head down in the PBS with one hand, and use your dominant hand to remove remaining thoracic, antennal, and mouthpart tissues still attached to the cuticle and to the developing head (Figure 2C). With your dominant hand, grab the trachea developing around each eye and pull it away;

- Holding the pupal head cuticle down with one hand, use your dominant hand to remove pieces of pupa cuticle around the developing head (Figure 5F), and gently detach the head from the cuticle by pushing it aside gently, or scraping it out of the cuticle (Figure 5G);

- When the developing head is completely detached from the pupa cuticle (Figure 5H), remove the non-brain head tissue, such as the ommatidia and the facets around the visual neuropils, and the developing mouth parts on the other side of the brain. Hold the brain in place with the forceps slightly opened, while pulling the non-brain tissue away with the other hand;

- If the brain (Figure 5I) is used for DNA or RNA extraction, grab it with the forceps and move it to the appropriate reagent ( $100 \%$ ethanol or RNAlater, respectively). If the brains are used for immunostaining, suck the brain up from the PBS with a pipette tip and transfer the brain into the fixative solution. Use a very small pipetting volume, large enough to lift the brain, but small enough to prevent taking an excess of PBS. This method will prevent damage or distortion of the brain tissue. 

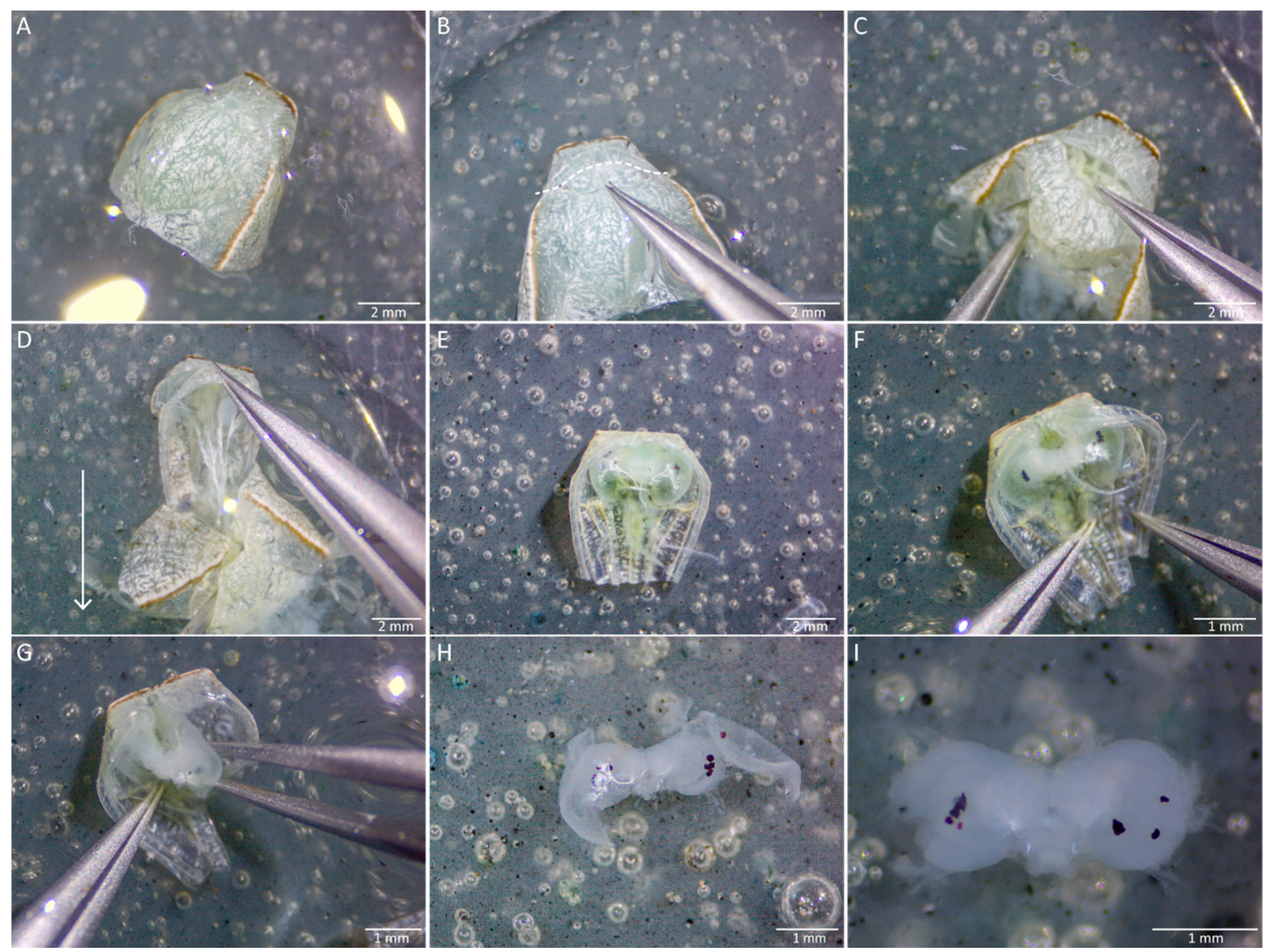

Figure 5. Dissection of a pupal brain at 30\% pupal development. (A) The anterior part of the pupa is submerged into $1 \times$ PBS. (B) The thorax cuticle is pushed down and (C) detached at the suture at the base of the head (along the dashed line) to make a small opening. (D) The thoracic tissue and cuticle are pulled away horizontally from the head tissue (following the direction of the arrow). (E) The developing head is visible at the bottom of the pupal cuticle. (F) Extra pieces of pupal cuticle are removed. (G) Then, the brain is gently scraped out. (H) While detached from the pupa cuticle, extra head tissue can be removed from the brain (e.g., cornea, antennae, trachea (seen in a bright white colour)). (I) The clean brain can be used for downstream analyses.

\section{Dissection of the Larval Brain and Gnathal Ganglion}

\subsection{Preparation for Dissection}

- Place the larvae on ice prior to dissection. After a few minutes, the larvae will become immobile and can be easily picked up with flat forceps;

- Wash the dissecting forceps, blade, and dissection plate with $70 \%$ ethanol. If the brains are used for RNA extraction, use RNAzap instead;

- Prepare Eppendorf tubes or well plates filled with the solution appropriate for the subsequent experiment conducted with the dissected brain and place them close to the dissection microscope. For DNA and RNA extraction, prepare tubes with about $300 \mu \mathrm{L}$ of $100 \%$ ethanol and RNAlater, respectively. For immunostaining experiments, place about $500 \mu \mathrm{L}$ of the fixative solution in the wells;

- Place a drop of cold PBS (about $500 \mu \mathrm{L}$, to cover the tissue fully) on the dissection plate. 


\subsection{Dissection Procedure}

- Using a scalpel blade, cut the head of the larvae and place it in a drop of PBS on the dissection plate (Figure 6A);

- $\quad$ Place the back of the head towards you and remove the extra thoracic tissue still attached to the hard cuticle (Figure 6B);

- With one hand, hold the head inside the drop of PBS by grabbing the cuticle at the opening. Remove small pieces of the head cuticle using the forceps on your other hand (Figure 6C). The cuticle is hard, so you can break little pieces with the tip of the forceps;

A CRITICAL STEP Do not pull the mandibles away from the head yet (Figures 2B and $6 \mathrm{D}$ ). They are attached to the gut, which goes towards the back of the head. passing just above the gnathal ganglion between the connectives (the tissue connecting the lobes and the gnathal ganglion). Pulling the mouthparts would tear the gnathal ganglion and possibly the brain itself, by pulling the connectives away from the brain tissue;

- When most of the back cuticle is removed, turn the head around and proceed to remove the cuticle on the front part of the head. Remove the antennae, the eyes, and other head components attached to the cuticle (Figure 2B). All head soft tissue, including the brain, will remain packed together. When most cuticle is removed, gently scrap the pack of head tissue (with the mandibles still attached) away from the remaining cuticle;

- By gently pulling away some head tissue (by grabbing them from the right and from the left), you can see the two brain lobes and the gnathal ganglion sitting in the middle (Figure 6E). They can be easily recognised from the other tissue, due to their oval shape, smooth texture, and white colour. After identifying the brain, grab and remove pieces of head tissue with one hand, while holding the mandibles with your other hand until the brain and the gnathal ganglion are well exposed. Alternatively, you can grab the group of soft tissue on the right with the corresponding hand, and the other side of the group of tissue with the left hand, and pull them towards opposite directions, freeing the brain placed in between. Pull gently and pay particular attention not to pull the connectives that link the brain with the gnathal ganglion;

- When the brain and the gnathal ganglion are well exposed, remove the other extra tissue still attached to them, by maintaining the brain with one hand through using the forceps slightly opened, and pulling the extra tissue away from it with the other hand. Sometimes, the brain and gnathal ganglion can be extracted directly from the head tissue, by pulling them gently with the forceps (Figure 6F). Small trachea (identified thanks to their shiny white colour) that are strongly attached to each brain lobe should be left in place, as they can tear the brain tissue if pulled away;

- Pick up the brain and the gnathal ganglion using a pipette and transfer them to the reagent appropriate for downstream experiments. 

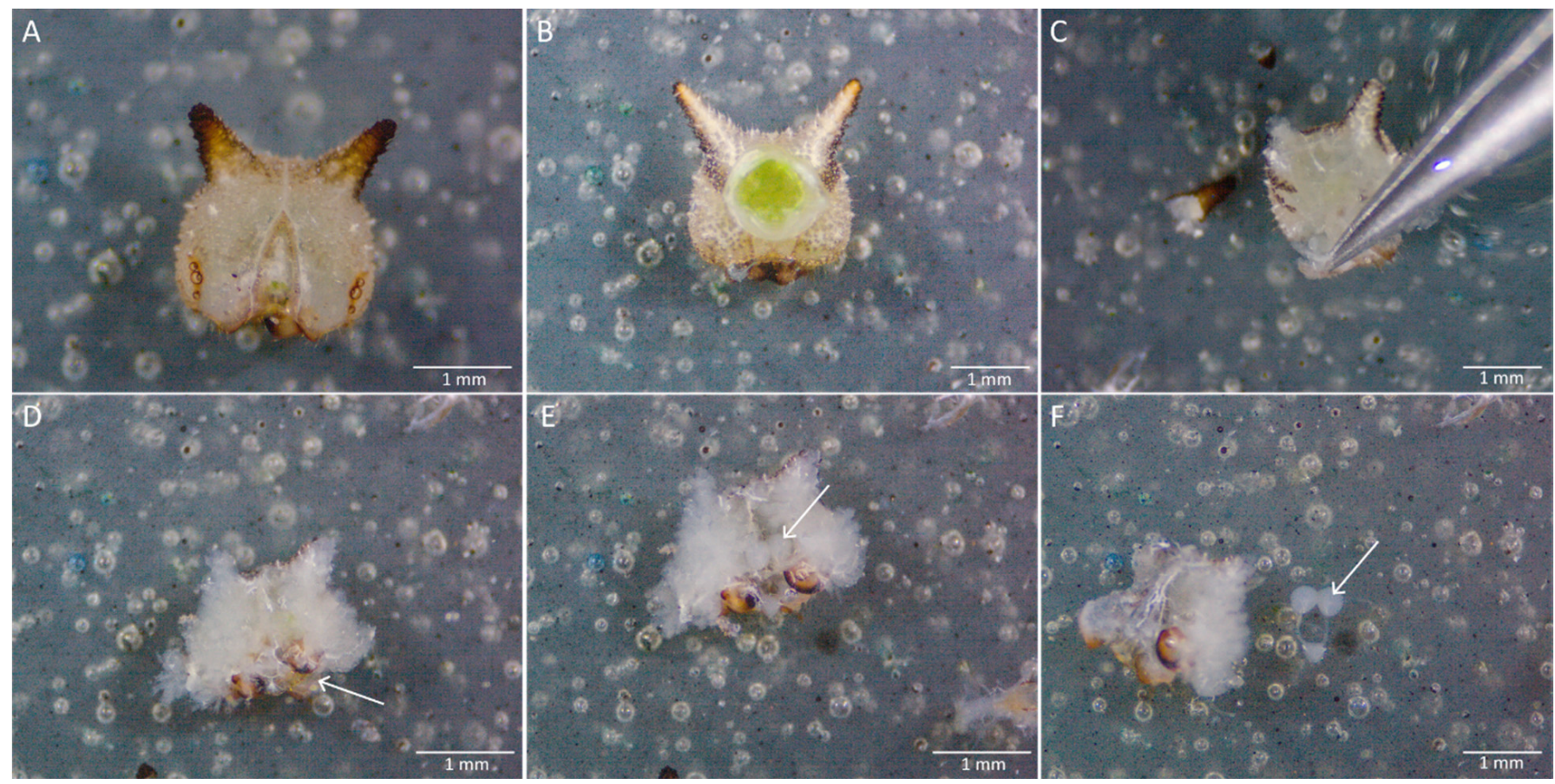

Figure 6. Dissection of the larval brain. (A) The head is cut out of the caterpillar body with a scalpel. (B) The head is turned face down for an easier dissection. (C) Pieces of cuticle are removed piece by piece around the head tissue. (D) The mandibles are left attached to the head tissue (arrow), as removing them might damage the brain (E). Gently pulling the head tissue on the right and left will create an opening, which exposes the brain (arrow). (F) The brain (arrow) attached to the gnathal ganglion (white mass below) can be gently pulled out after removing the pieces of head tissue around it and picked up with a pipette for further downstream experiments.

\section{Expected Results}

\subsection{Adult Brain}

The adult brain is made up of two optic lobes and a central mass, which are clearly defined (Figure 7A). A more in-depth visualisation of the brain anatomy can be achieved through immunostaining, using an antibody targeting synapsin (involved in the regulation of neurotransmitter release at synapses) and confocal microscopy techniques. In brief, the optic lobes consist of five paired neuropils, which are clearly defined: the lamina (La), medulla (Me), accessory medulla (aMe), lobula (Lo), and lobula plate (LoP). The central brain consists of five paired and one unpaired neuropils, which are also clearly defined: the antennal lobes $(\mathrm{AL})$, anterior optic tubercles (AOTu), mushroom body lobes (MB-lb) and calyx (MB-ca), protocerebral bridge (PB), and the central body (CB) (Figure 7B-F).

The extraction of a single dissected adult brain using the Rneasy Plus Mini Kit (Qiagen, Singapore) yielded an average of $4500 \mathrm{ng}$ of mRNA, which is a sufficiently large amount for further experiments (e.g., qPCR, RNAseq).

\subsection{Pupal Brain}

Similar to the adult brain, the pupal brain also consists of two optic lobes and a central mass which are clearly defined. Visualisation under immunostaining (targeting synapsin) shows three paired neuropils in the optic lobes and five paired and one unpaired neuropil in the central brain. In brief, the neuropils visualised in the optic lobes are the medulla $(\mathrm{Me})$, accessory medulla (aMe), and the lobula (Lo) (Figure 8B,C). In the central brain, the paired neuropils are the antennal lobes $(\mathrm{AL})$, anterior optic tubercles $(\mathrm{AOTu})$, mushroom body lobes (MB-lb) and calyx (MB-ca), protocerebral bridge (PB), and the central body (CB) (Figure $8 \mathrm{~A}, \mathrm{~B}, \mathrm{D})$. However, the AL and the MB-ca are not as well-defined or well-developed in the pupal brain than as in the adult brain. 


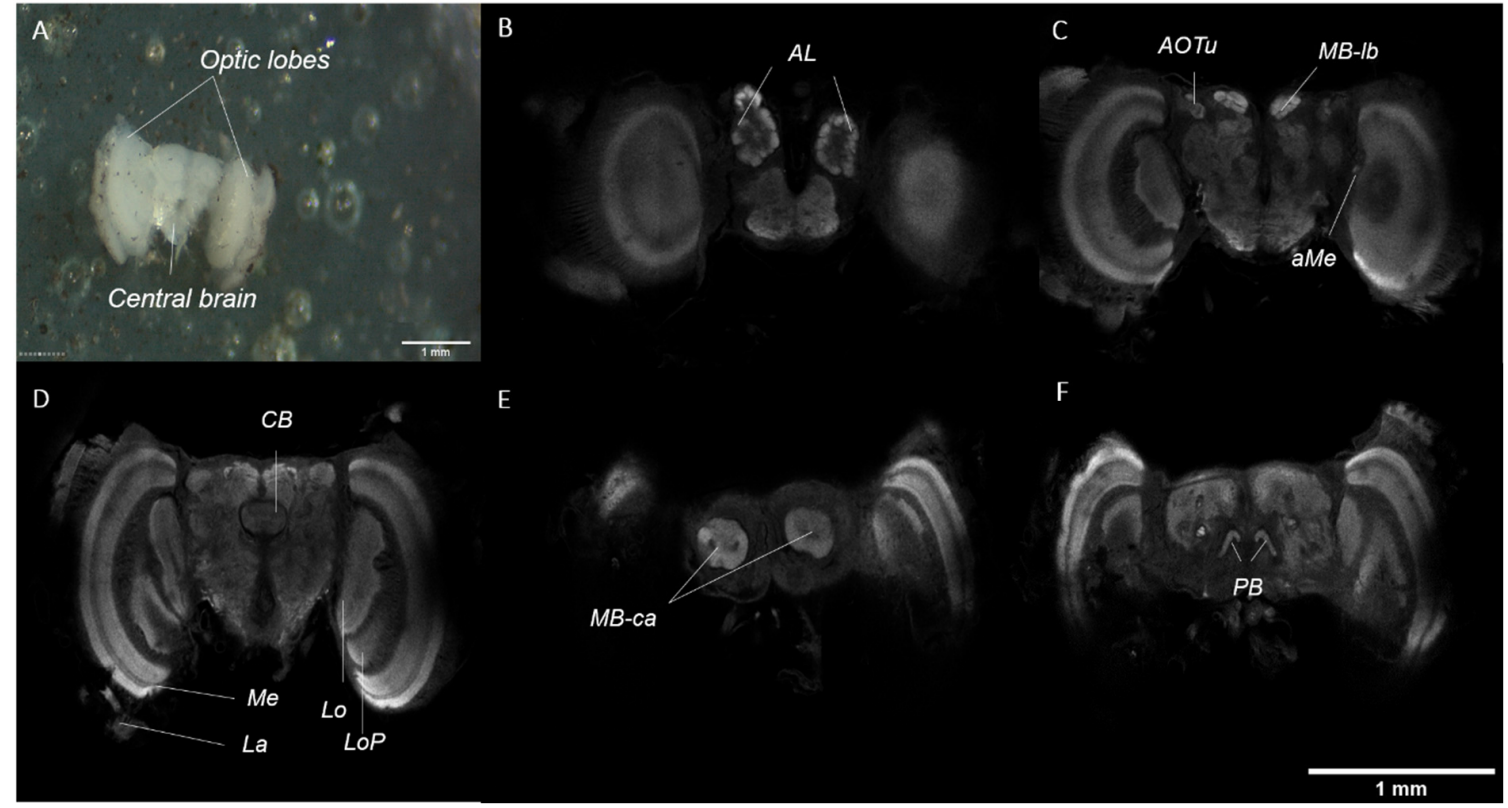

Figure 7. (A) Adult brain after dissection, showing the two optic lobes and the central brain (B-F). Visualisation of the adult brain, immunostained with an antibody against synapsin, in different confocal sections from most anterior (B) to most posterior (F). (B) Antennal lobes (AL). (C) Accessory medulla (aMe), anterior optic tubercles (AOTu), and mushroom body lobes (MB-lb). (D) Lamina (La), medulla (Me), the lobula (Lo), lobula plate (LoP), and the central body (CB). (E) Mushroom body calyx (MB-ca). (F) Protocerebral bridge (PB).

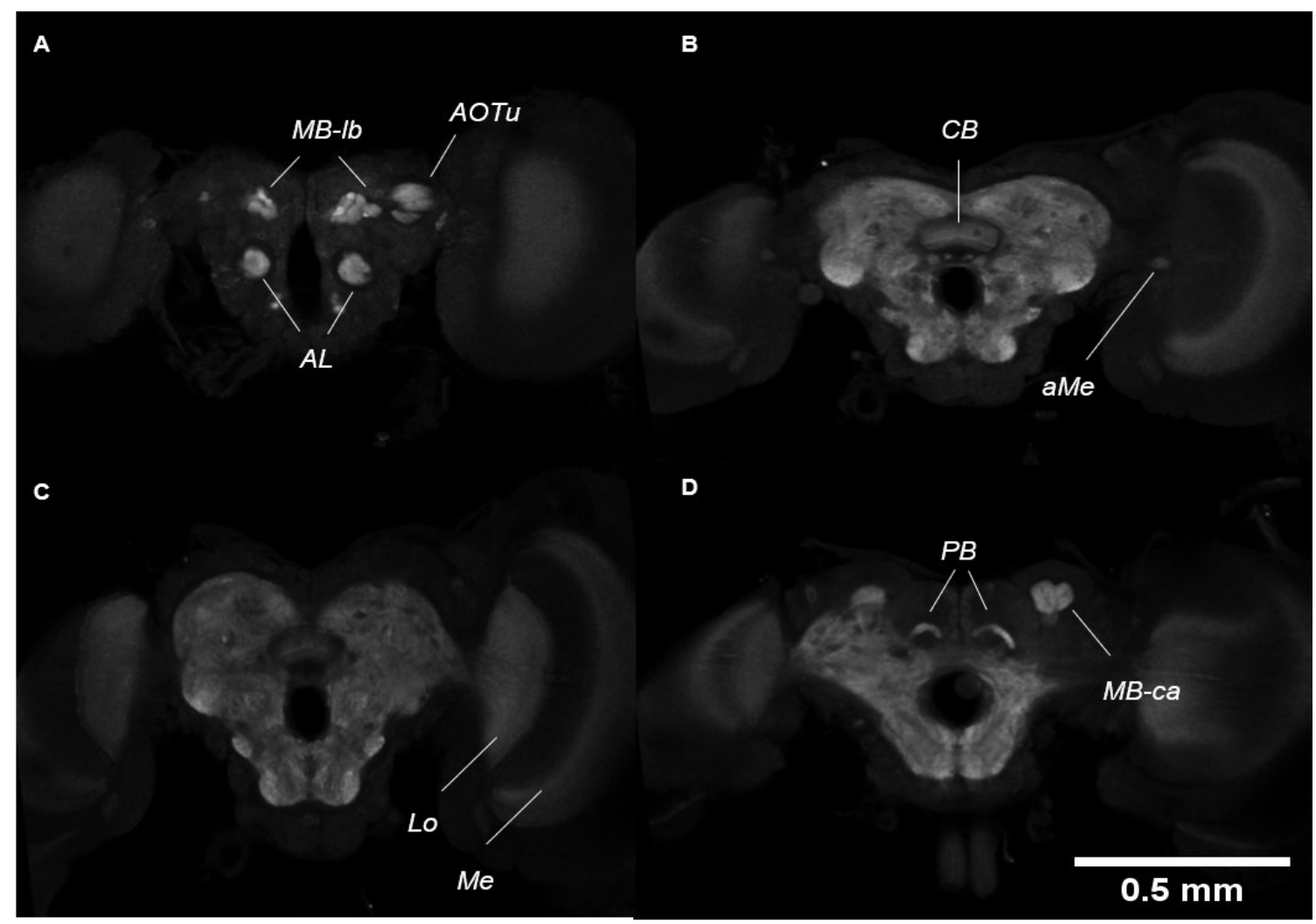

Figure 8. Visualisation of the pupal brain in different confocal sections from most anterior (A) to most posterior (D) stained with synapsin. (A) Mushroom body lobes (MB-lb), anterior optic tubercles (AOTu), and antennal lobes (AL). (B) Central body (CB) and accessory medulla (aMe). (C) Medulla (Me) and lobula (Lo). (D) Mushroom body calyx (MB-ca) and protocerebral bridge (PB). 
The extraction of a single dissected pupal brain using the Rneasy Plus Mini Kit (Qiagen, Singapore) yielded an average of $3000 \mathrm{ng}$ of mRNA, a sufficiently large amount that can be used for further experiments (e.g., qPCR, RNAseq).

\subsection{Larval Brain}

The larval brain appears relatively different from the adult and pupal brains. The larval brain consists of two fused lobes connected dorsally to a ventral ganglion by connective tissues. Further analysis of the brain by immunostaining did not reveal any defined neuropils (Figure 9).

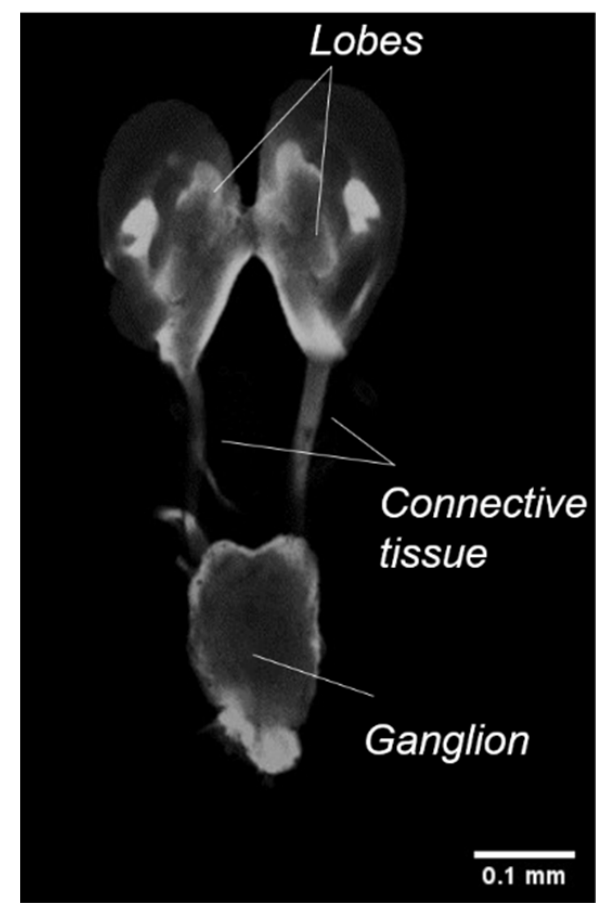

Figure 9. Visualisation of the larval brain, immunostained with an antibody against synapsin in a single confocal section, showing the lobes, connective tissues, and ganglion.

The extraction of a single dissected larval brain using the Rneasy Plus Mini Kit (Qiagen, Singapore) yielded an average of $1000 \mathrm{ng}$ of mRNA. This amount is sufficient for subsequent qPCR analysis. Several larval brains can be pooled into one tube, to get a higher RNA yield as required by some sequencing companies.

\subsection{Brains of Other Butterfly Species}

We applied our dissection procedure to brains of other species from different families and of various sizes. We successfully dissected the brain of Pieris canidia at the same stages as in B. anynana: adult, 30\% pupal development, and 5th instar larva (Figure 10A-D). We also successfully dissected the brains of Malayan eggfly adults (Nymphalidae) (Figure 10E,F) and of Papilio sp butterflies (Papilionidae) (Figure 10G,H). 


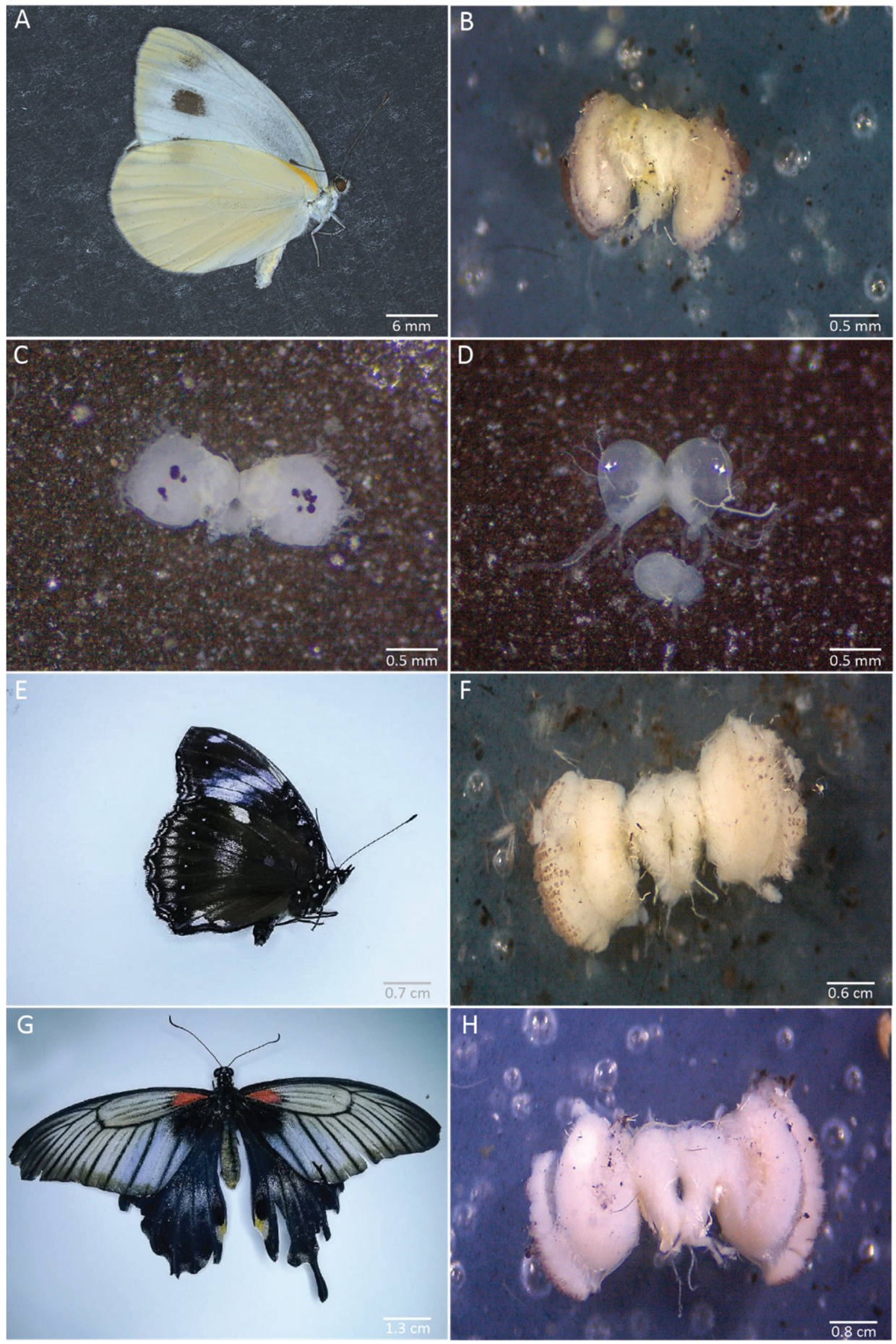

Figure 10. Brains dissected from Pieris canidia, Hypolimnas anomala, and Papilio sp. (A-C) Pieris canidia brain at the adult stage (fixed brain, B), at 30\% pupal development (not fixed, C), and the 5th instar larval stage (not fixed, D). (F) Adult brain from Hypolimnas anomala (Nymphalidae, E). (H) Adult brain from Papilio sp (Papilionidae, G).

\section{Reagents}

7.1. Preparation of HEPES-Buffered Saline (HBS)

- $\quad$ Add $800 \mathrm{~mL}$ of MilliQ water and reagents mentioned in Table 1 to a 1 L glass bottle; 
Table 1. Reagents used to make 1 L of HBS.

\begin{tabular}{cc}
\hline Reagents & Amount $(\mathbf{g})$ \\
\hline $\mathrm{NaCl}$ & 8.77 \\
$\mathrm{KCl}$ & 3.73 \\
$\mathrm{CaCl}_{2}$ & 5.55 \\
Sucrose & 8.56 \\
$\mathrm{HEPES}$ & 2.38 \\
\hline
\end{tabular}

- Measure the $\mathrm{pH}$ of the solution using a $\mathrm{pH}$ metre, and adjust accordingly with drops of $\mathrm{HCl}$ and $\mathrm{NaOH}$ until the solution has a $\mathrm{pH}$ of 7.4;

- Then, add MilliQ water until the volume in the bottle reaches $1 \mathrm{~L}$;

- Autoclave the solution and store it at $4{ }^{\circ} \mathrm{C}$ thereafter.

7.2. Preparation of $10 \times$ Phosphate-Buffered Saline (PBS)

- Add $800 \mathrm{~mL}$ of MilliQ water and reagents mentioned in Table 2 to a $1 \mathrm{~L}$ glass bottle;

Table 2. Reagents used to make $1 \mathrm{~L}$ of $10 \times$ PBS.

\begin{tabular}{cc}
\hline Reagents & Amount (g) \\
\hline $\mathrm{NaCl}$ & 81.80 \\
$\mathrm{KH}_{2} \mathrm{PO}_{4}$ & 5.28 \\
$\mathrm{~K}_{2} \mathrm{HPO}_{4}$ & 10.68 \\
\hline
\end{tabular}

- Measure the $\mathrm{pH}$ of the solution using a $\mathrm{pH}$ metre and adjust accordingly with drops of $\mathrm{HCl}$ and $\mathrm{NaOH}$ until the $\mathrm{pH}$ is around 6.8;

- Add MilliQ water until the volume in the bottle reaches $1 \mathrm{~L}$;

- Autoclave the solution and store it at $4{ }^{\circ} \mathrm{C}$ thereafter;

- For the preparation of $100 \mathrm{~mL}$ of $1 \times$ PBS, dilute $10 \mathrm{~mL}$ of $10 \times$ PBS into $90 \mathrm{~mL}$ of MilliQ water.

7.3. Preparation of Zinc Formaldehyde (ZnFA)

- Add $800 \mathrm{~mL}$ of MilliQ water and reagents mentioned in Table 3 to a $1 \mathrm{~L}$ glass bottle;

Table 3. Reagents used to make $1 \mathrm{~L}$ of ZnFA.

\begin{tabular}{cc}
\hline Reagents & Amount \\
\hline $\mathrm{ZnCl}$ & $2.51 \mathrm{~g}$ \\
$\mathrm{NaCl}$ & $7.89 \mathrm{~g}$ \\
Sucrose & $11.98 \mathrm{~g}$ \\
$4 \%$ Formaldehyde & $10 \mathrm{~mL}$ \\
\hline
\end{tabular}

- Measure the $\mathrm{pH}$ of the solution using a $\mathrm{pH}$ metre and adjust accordingly with drops of $\mathrm{HCl}$ and $\mathrm{NaOH}$ until the $\mathrm{pH}$ is 6.35;

- Add MilliQ water until the volume in the bottle reaches $1 \mathrm{~L}$ and autoclave the solution for $20 \mathrm{~min}$ at $121^{\circ} \mathrm{C}$;

- $\quad$ Add $4 \%$ Formaldehyde and store it at $4{ }^{\circ} \mathrm{C}$;

- For the preparation of $4 \%$ Formaldehyde, dilute $10 \mathrm{~mL}$ of $16 \%$ Formaldehyde in $30 \mathrm{~mL}$ of $1 \times$ PBS.

Author Contributions: Conceptualisation, Y.P.T., E.D. and A.M.; methodology, Y.P.T. and E.D.; writing-original draft preparation, Y.P.T. and E.D.; writing—review and editing, E.D. and A.M.; video recording and editing, Y.P.T. and E.D.; funding acquisition, E.D. and A.M.; equal contribution, Y.P.T. and E.D. All authors have read and agreed to the published version of the manuscript. 
Funding: This research was supported by the Ministry of Education (MOE) Singapore, award MOE2018-T2-1-092 and by the NUS Resilience and Growth Initiative funded by the SG United Traineeship Program, Singapore.

Data Availability Statement: All the data collected during this study are available in the article.

Acknowledgments: The authors thank T.D. Banerjee for his help in using the microscope and the recording of the butterfly brain dissection videos; L. Guyonvarch for his guidance in editing the caterpillar and pupal brain dissection videos; J. Wee and T.D. Banerjee for providing extra butterfly species; the Firefly Farm for providing the caterpillar food; and anonymous reviewers that helped in improving the manuscript.

Conflicts of Interest: The authors declare no conflict of interest. The funders had no role in the design of the study; in the collection, analyses, or interpretation of data; in the writing of the manuscript, or in the decision to publish the results.

\section{References}

1. Chittka, L.; Niven, J. Are Bigger Brains Better? Curr. Biol. 2009, 19, R995-R1008. [CrossRef] [PubMed]

2. Dukas, R. Evolutionary Biology of Insect Learning. Annu. Rev. Ė̀ntomol. 2008, 53, 145-160. [CrossRef]

3. Giurfa, M. Cognition with few neurons: Higher-order learning in insects. Trends Neurosci. 2013, 36, 285-294. [CrossRef]

4. Avargues-Weber, A.; Dyer, A.G.; Combe, M.; Giurfa, M. Simultaneous mastering of two abstract concepts by the miniature brain of bees. Proc. Natl. Acad. Sci. USA 2012, 109, 7481-7486. [CrossRef] [PubMed]

5. Hansell, M.; Ruxton, G.D. Setting tool use within the context of animal construction behaviour. Trends Ecol. Evol. 2008, 23, 73-78. [CrossRef]

6. Sheehan, M.J.; Tibbetts, E.A. Specialized Face Learning Is Associated with Individual Recognition in Paper Wasps. Science 2011, 334, 1272-1275. [CrossRef] [PubMed]

7. Tibbetts, E.A.; Dale, J. A socially enforced signal of quality in a paper wasp. Nat. Cell Biol. 2004, 432, 218-222. [CrossRef]

8. Giurfa, M. An Insect's Sense of Number. Trends Cogn. Sci. 2019, 23, 720-722. [CrossRef]

9. Howard, S.R.; Avarguès-Weber, A.; Garcia, J.E.; Greentree, A.D.; Dyer, A.G. Achieving arithmetic learning in honeybees and examining how individuals learn. Commun. Integr. Biol. 2019, 12, 166-170. [CrossRef]

10. Roeder, K.D. Episodes in Insect Brains: How do animals select modes of behavior adapted to immediate circumstances? A mechanism is sought by probing the brains of insects. Am. Sci. 1970, 58, 378-389.

11. Howse, P. Brain Structure and Behavior in Insects. Annu. Rev. Èntomol. 1975, 20, 359-379. [CrossRef]

12. Chittka, L.; Giurfa, M.; Riffell, J.A. Editorial: The Mechanisms of Insect Cognition. Front. Psychol. 2019, 10, 2751. [CrossRef]

13. Rutzler, M.; Zwiebel, L.J. Molecular biology of insect olfaction:recent progress and conceptual models. J. Comp. Physiol. A 2005, 191, 777-790. [CrossRef] [PubMed]

14. Ramdya, P.; Schneider, J.; Levine, J.D. The neurogenetics of group behavior in Drosophila melanogaster. J. Exp. Biol. 2017, 220, 35-41. [CrossRef] [PubMed]

15. Lee, S.S.; Wu, M.N. Neural circuit mechanisms encoding motivational states in Drosophila. Curr. Opin. Neurobiol. 2020, 64, 135-142. [CrossRef] [PubMed]

16. Wilson, R.I. Early Olfactory Processing inDrosophila: Mechanisms and Principles. Annu. Rev. Neurosci. 2013, 36, $217-241$. [CrossRef]

17. De Ibarra, N.H.; Vorobyev, M.; Menzel, R. Mechanisms, functions and ecology of colour vision in the honeybee. J. Comp. Physiol. A 2014, 200, 411-433. [CrossRef] [PubMed]

18. Paoli, M.; Galizia, G.C. Olfactory coding in honeybees. Cell Tissue Res. 2021, 383, 35-58. [CrossRef] [PubMed]

19. Bestea, L.; Réjaud, A.; Sandoz, J.; Carcaud, J.; Giurfa, M.; Sanchez, M.G.D.B. Peripheral taste detection in honey bees: What do taste receptors respond to? Eur. J. Neurosci. 2021, 1-28. [CrossRef]

20. Mizunami, M.; Matsumoto, Y. Roles of Octopamine and Dopamine Neurons for Mediating Appetitive and Aversive Signals in Pavlovian Conditioning in Crickets. Front. Physiol. 2017, 8, 1027. [CrossRef]

21. Schöneich, S. Neuroethology of acoustic communication in field crickets-from signal generation to song recognition in an insect brain. Prog. Neurobiol. 2020, 194, 101882. [CrossRef]

22. Römer, H. Insect acoustic communication: The role of transmission channel and the sensory system and brain of receivers. Funct. Ecol. 2020, 34, 310-321. [CrossRef]

23. Konopka, J.K.; Task, D.; Afify, A.; Raji, J.; Deibel, K.; Maguire, S.; Lawrence, R.; Potter, C.J. Olfaction in Anopheles mosquitoes. Chem. Senses 2021, 46. [CrossRef]

24. Nishino, H.; Iwasaki, M.; Paoli, M.; Kamimura, I.; Yoritsune, A.; Mizunami, M. Spatial Receptive Fields for Odor Localization. Curr. Biol. 2018, 28, 600-608.e3. [CrossRef] [PubMed]

25. Domae, M.; Iwasaki, M.; Mizunami, M.; Nishino, H. Functional unification of sex pheromone-receptive glomeruli in the invasive Turkestan cockroach derived from the genus Periplaneta. Neurosci. Lett. 2019, 708, 134320. [CrossRef] 
26. Couto, A.; Wainwright, J.B.; Morris, B.J.; Montgomery, S.H. Linking ecological specialisation to adaptations in butterfly brains and sensory systems. Curr. Opin. Insect Sci. 2020, 42, 55-60. [CrossRef]

27. Arikawa, K. The eyes and vision of butterflies. J. Physiol. 2017, 595, 5457-5464. [CrossRef] [PubMed]

28. Carlsson, M.; Schäpers, A.; Nässel, D.R.; Janz, N. Organization of the Olfactory System of Nymphalidae Butterflies. Chem. Senses 2013, 38, 355-367. [CrossRef] [PubMed]

29. Mikhail, A.; Lewis, J.E.; Yack, J.E. What does a butterfly hear? Physiological characterization of auditory afferents in Morpho peleides (Nymphalidae). J. Comp. Physiol. A 2018, 204, 791-799. [CrossRef]

30. Xu, W. How do moth and butterfly taste?-Molecular basis of gustatory receptors in Lepidoptera. Insect Sci. 2020, 27, 1148-1157. [CrossRef]

31. Dell'Aglio, D.D.; Losada, M.E.; Jiggins, C.D. Butterfly Learning and the Diversification of Plant Leaf Shape. Front. Ecol. Evol. 2016, 4, 4. [CrossRef]

32. Balamurali, G.S.; Edison, A.; Somanathan, H.; Kodandaramaiah, U. Spontaneous colour preferences and colour learning in the fruit-feeding butterfly, Mycalesis mineus. Behav. Ecol. Sociobiol. 2019, 73, 39. [CrossRef]

33. Rossi, M.; Hausmann, A.E.; Thurman, T.J.; Montgomery, S.H.; Papa, R.; Jiggins, C.D.; McMillan, W.O.; Merrill, R.M. Visual mate preference evolution during butterfly speciation is linked to neural processing genes. Nat. Commun. 2020, 11, 1-10. [CrossRef] [PubMed]

34. Van Schooten, B.; Meléndez-Rosa, J.; Van Belleghem, S.M.; Jiggins, C.D.; Tan, J.D.; McMillan, W.O.; Papa, R. Divergence of chemosensing during the early stages of speciation. Proc. Natl. Acad. Sci. USA 2020, 117, 16438-16447. [CrossRef]

35. Montgomery, S.H.; Merrill, R.M.; Ott, S.R. Brain composition inHeliconiusbutterflies, posteclosion growth and experiencedependent neuropil plasticity. J. Comp. Neurol. 2016, 524, 1747-1769. [CrossRef] [PubMed]

36. Van Dijk, L.J.A.; Janz, N.; Schäpers, A.; Gamberale-Stille, G.; Carlsson, M.A. Experience-dependent mushroom body plasticity in butterflies: Consequences of search complexity and host range. Proc. R. Soc. B Biol. Sci. 2017, 284. [CrossRef]

37. Snell-Rood, E.C.; Swanson, E.M.; Seabloom, E.W.; Borer, E.T.; Espeset, A.; Jaumann, S.; Philips, K.; Walker, C.; Semke, B.; Mori, A.S.; et al. Nutritional constraints on brain evolution: Sodium and nitrogen limit brain size. Evolution 2020, 74, 2304-2319. [CrossRef]

38. Kelly, S.M.; Elchert, A.; Kahl, M. Dissection and Immunofluorescent Staining of Mushroom Body and Photoreceptor Neurons in Adult Drosophila melanogaster Brains. J. Vis. Exp. 2017, e56174. [CrossRef]

39. Wu, J.S.; Luo, L. A protocol for dissecting Drosophila melanogaster brains for live imaging or immunostaining. Nat. Protoc. 2006, 1, 2110-2115. [CrossRef]

40. Sweeney, S.T.; Hidalgo, A.; De Belle, J.S.; Keshishian, H. Dissection of AdultDrosophilaBrains. Cold Spring Harb. Protoc. 2011, 2011, 066878. [CrossRef] [PubMed]

41. Tito, A.J.; Cheema, S.; Jiang, M.; Zhang, S. A Simple One-step Dissection Protocol for Whole-mount Preparation of Adult Drosophila Brains. J. Vis. Exp. 2016, 10, 55128. [CrossRef]

42. Williamson, W.R.; Hiesinger, P.R. Preparation of Developing and Adult Drosophila Brains and Retinae for Live Imaging. J. Vis. Exp. 2010, 37, e1936. [CrossRef]

43. Robertson, K.; Monteiro, A. Female Bicyclus anynana butterflies choose males on the basis of their dorsal UV-reflective eyespot pupils. Proc. R. Soc. B Boil. Sci. 2005, 272, 1541-1546. [CrossRef]

44. Nieberding, C.M.; De Vos, H.; Schneider, M.V.; Lassance, J.-M.; Estramil, N.; Andersson, J.; Bång, J.; Hedenström, E.; Löfstedt, C.; Brakefield, P.M. The Male Sex Pheromone of the Butterfly Bicyclus anynana: Towards an Evolutionary Analysis. PLoS ONE 2008, 3, e2751. [CrossRef]

45. Prudic, K.L.; Jeon, C.; Cao, H.; Monteiro, A. Developmental Plasticity in Sexual Roles of Butterfly Species Drives Mutual Sexual Ornamentation. Science 2011, 331, 73-75. [CrossRef]

46. Huq, M.; Bhardwaj, S.; Monteiro, A. Male Bicyclus anynana Butterflies Choose Females on the Basis of Their Ventral UV-Reflective Eyespot Centers. J. Insect Sci. 2019, 19, 25. [CrossRef] [PubMed]

47. Westerman, E.L.; Hodgins-Davis, A.; Dinwiddie, A.; Monteiro, A. Biased learning affects mate choice in a butterfly. Proc. Natl. Acad. Sci. USA 2012, 109, 10948-10953. [CrossRef] [PubMed]

48. Dion, E.; Pui, L.X.; Weber, K.; Monteiro, A. Early-exposure to new sex pheromone blends alters mate preference in female butterflies and in their offspring. Nat. Commun. 2020, 11, 1-8. [CrossRef] [PubMed]

49. Gowri, V.; Dion, E.; Viswanath, A.; Piel, F.M.; Monteiro, A. Transgenerational inheritance of learned preferences for novel host plant odors inBicyclus anynanabutterflies. Evolution 2019, 73, 2401-2414. [CrossRef]

50. Bear, A.; Prudic, K.; Monteiro, A. Steroid hormone signaling during development has a latent effect on adult male sexual behavior in the butterfly Bicyclus anynana. PLoS ONE 2017, 12, e0174403. [CrossRef]

51. Bear, A.; Monteiro, A. Male Courtship Rate Plasticity in the Butterfly Bicyclus anynana Is Controlled by Temperature Experienced during the Pupal and Adult Stages. PLoS ONE 2013, 8, e64061. [CrossRef] [PubMed] 